\title{
The Silent and Neglected Crisis of Malnutrition: Scientific Evidence for Taking Decisive Action
}

\author{
UCHENDU Florence Ngozi \\ School of Science and Technology, National Open University of Nigeria \\ 14/16 Ahmadu Way, Victoria Island, Opp. Bonny Cantonment, Lagos, Nigeria \\ Tel: 234-803-706-5874 E-mail: Uchendu_flo@yahoo.com
}

ATINMO Tola

Department of Human Nutrition, Faculty of Public Health

College of Medicine, University of Ibadan, Ibadan, Nigeria

Tel: 234-802-324-5055 E-mail: tola_atinmo@yahoo.com

Received: September 17, $2010 \quad$ Accepted: October 12, 2010 doi:10.5539/gjhs.v3n1p193

\begin{abstract}
Malnutrition is a global crisis especially in developing countries. Micronutrient deficiency is a "hidden hunger" and as such has been neglected over the years leading to malnutrition crisis. Nigeria is one of the developing countries that are experiencing malnutrition crisis. This paper therefore highlights scientific evidence of positive impact of micronutrients on human function and proven sets of nutrition intervention strategies as a stimulus for taking decisive action to combat malnutrition.
\end{abstract}

Keywords: Nigeria, Malnutrition crisis, Scientific evidence, Nutrition strategy

\section{Introduction}

The word malnutrition is from two words-Mal and nutrition. Mal means bad, a disease or a disorder. Malnutrition is therefore bad nutrition, disease or disorder associated with nutrition. Malnutrition is a condition of impaired development caused by either a long-term deficiency or an excess in energy and or nutrient intake (Wardlaw and Kessel, 2002). Malnutrition is a state where adequate nutrients are not delivered to the cells to provide the substrate for optimal functioning. It is also a state where more nutrients than the cell's needs are consumed creating excess which become injurious to the cells (Akinyele, 2005). There are about 45 nutrients the body needs and must be supplied to the body daily at the right quantities. Inadequate eating habits, excessive intake and metabolic defects in relation to the Recommended Daily Allowance of these nutrients will result in malnutrition. More recently, malnutrition is defined as an unintentional weight loss of more than $10 \%$ associated with a serum albumin level below $3.2 \mathrm{~g} / \mathrm{dL}$ (Joshi, 2003).

Malnutrition could be classified according to the nature of the nutrients involved and dietary intake of the nutrients. According to the nature of the nutrients involved, malnutrition could be due to macronutrient or micronutrient deficiencies (vitamin and mineral deficiency). Macronutrient malnutrition is associated with either energy (calorie) or protein deficiency while micronutrient deficiency is as a result of inadequacy in vitamin and mineral requirements of the body. Excessive or inadequate intake of macro and micro-nutrients could result in either over- or under-nutrition. When the food supplies are ample or over abundant, incorrect food choices coupled with an excessive intake can lead to overnutrition. Overnutrition could manifest as chronic diseases such as obesity, type 2 diabetes, atherosclerosis and hypervitaminosis. This is more common in developed countries. For example, overweight and obese children and adolescents are becoming more prevalent in urban areas of Vietnam (Tang, 2006). When food supplies are low and the population is large, undernutrition is the resultant effect. Undernutrition is therefore due to chronic hunger (starvation), bodily deprivation or lack of nutrients which could be hidden and occasioned by poverty, famine, war, etc. It is found not only among people in the developing world but also among many people living at or below the poverty level in developed countries. It is the most common form of malnutrition among the poor in both developing and developed World. However, undernutrition is most prevalent in developing countries. While affluent, industrialized countries are more 
concerned with the adverse effects of excessive food or nutrient intake, poor developing nations continue to grapple with food shortages and nutritional deficiency diseases. These include macronutrient disorders such as Protein-Energy Malnutrition (PEM) or Protein-Calorie Malnutrition (PCM) and various vitamin and mineral deficiencies such as vitamin A deficiency (VAD) called night blindness or nyctalopia, xerophthalmia (blindness), nutritional anaemia, endemic goiter, zinc deficiency and folic acid deficiency. All these forms of malnutrition have debilitating consequences on a countries population and economy in terms of productivity and Gross Domestic Product (GDP).

\section{Is there Global Malnutrition Crisis?}

Malnutrition is a major public health problem in many parts of the world. It has been estimated that over $43 \%$ of children worldwide are stunted (Sedgh, et al. 2000). The United States has the largest number of children living in poverty (14 million under the age of 19). About one out of every six children in this country goes hungry or is at risk of inadequate food (Wardlaw and Kessel, 2002).

Micronutrient malnutrition is the world's most prevalent and most devastating nutritional problem. The statistics are astounding: more than two billion people worldwide are prevented from achieving their full potential because of it. Deficiencies in vitamin A, iron and iodine cause innumerable maternal and childhood deaths, and leave millions of survivors blinded or mentally retarded. Even less severe deficiencies impair intelligence and strength, reducing working capacity and productivity, and impeding economic development (Bowley, 1997). Vitamin and mineral deficiencies deprive 1 billion people world-wide of their intellect, strength and vitality (UNICEF/MI, 2006). Vitamin and mineral (VM) deficiency is not a problem only for the poor: Iron deficiency still affects $10 \%$ of the population in developed nations. Iodine deficiency remains a matter of concern in countries like Germany and Spain. Folate deficiency is still causing birth defects in Europe, and in Australia and New Zealand, where flour is not fortified with folic acid. World-wide, VM deficiency is to be found not only in poor and remote rural areas but in the middle class suburbs of capital cities (UNICEF/MI, 2006). There is a global malnutrition crisis even though the prevalence of VM deficiency is higher in developing countries than in developed countries.

Child malnutrition, an important indicator of food insecurity, has steadily increased in Africa over the past 30 years, from approximately 27 percent in the 1970s to over 33 percent in recent years (InterAcademy Council, 2004) (Fig. 1.). By 2025, hunger could be a daily reality for nearly 42 million children in Africa (Braun, 2005). Micronutrient malnutrition is widespread in Africa, affecting many people of all ages and socioeconomic groups especially infants, pre-school children, adolescents, pregnant women, and lactating mothers. The alarmingly high under-5 mortality rates in several West African countries are attributable to gross under-nutrition and micronutrient deficiencies, especially vitamin A deficiency (Begin and Greig, 2002). World Health Report (1) identified iodine, iron, vitamin A and zinc deficiencies among the world's most serious health risk factors (FFI, 2008; McGuire, 2008). There is mounting evidence of widespread vitamin B12 depletion and deficiency in many population groups that consume low amounts of animal source foods, the only natural source of B12 (Black, 2003; FFI, 2008). Vitamin A deficiency (VAD) is a global public health problem in about 78 developing countries (Liberato and Sant'Ana, 2006; Thakore and Gopalswamy, 2006; Semba and Bloem, 2002; Pineda, 1998). Out of the $127.2 \mathrm{~m}$ VAD deficient children, $25 \%$ represents pre-school aged children in high-risk regions of the developing world, including one developed country destabilized by social conflict while $26 \%$ live in Africa. $4 \%$ of the world's xerophthalmic children live in each of these countries- Nigeria, Afghanistan, and China (West, 2002; Miller et al. 2002).

\section{Prevalence of Malnutrition in Nigeria}

Nigeria is the $7^{\text {th }}$ largest World oil producing country yet is bedeviled by all these forms of malnutrition. The score sheet for welfare indicators in Nigeria is poor. The poverty level in the country has nosedived from $46-77 \%$ in the last 13 decades. It is widely accepted that no less than $54 \%$ of Nigerians live below the poverty line (Falase, 2004). The household food security in Nigeria has moved from $68 \%$ in 2003 to $70 \%$ in 2006 (Maziya-Dixon, Akinyele et al. 2003; Sanusi et al. 2006). Lip-service is being paid to poverty in the various poverty alleviation programmes purportedly being carried out in the country e.g. distribution of bags of garri to residents of a Local Government. Welfare programmes that will empower the citizenry to catch fish rather than receive fish all the time will help checkmate malnutrition. Almost half of the world's people earn less than $\$ 200$ a year and many use $90-90 \%$ of that income to obtain food. About $\$ 2000$ to $\$ 3000$ of income each year is needed for a person to reach the life expectancy seen in the United States (Wardlaw and Kessel, 2002). The pay packet cannot take many Nigerians home. The most common poverty lines for International comparisms among countries are US $\$ 1$ a day for low-income countries, US $\$ 2$ for middle-income, and US $\$ 4$ for transition economies (OECD, 2001). Many Nigerians survive on less than US\$2 per day. 
Nigeria has been rated $187^{\text {th }}$ out of the 191 member states of the WHO performance rating for health system. The life expectancy for men is 48 years and 52years for women (Akinyele, 2005). According to Falase (2005), it has been shown that a newborn in Nigeria can expect to have about 41 years of healthy life, compared to 50 in Ghana, 50 in Gambia, 50 in India, and 60 in Brazil. Yet except India and Brazil, Nigeria is the giant of Africa. This is worsened by the fact that physicians cannot go round the population. Number of physicians (per 100,000 people) is put at 19 . The percentage of undernourished people (as percentage of total population) is $7 \%$.

These records prove that there is a malnutrition crisis in Nigeria. Nigerians are passing through excruciating pains of hunger, starvation and poverty occasioned by huge unemployment, poor social infrastructures, neglected and dilapidated health care system, poor road networks, zero agricultural scheme and industrial investment. All these result to high inflation thereby making the little food products available expensive and unaffordable to the poor masses who constitute the majority of the population. These indicators show that Nigeria has indeed sunk into a quagmire from which she needs urgent rescue (Akinyele, 2005). One of the consequences of hunger, starvation and poverty in the country is malnutrition. The major malnutrition in the country is Protein Energy Malnutrition (PEM), Vitamin A deficiency (VAD), Iron deficiency anaemia (IDA), and Iodine deficiency disorder (IDD) (Table 1).

\subsection{Profiles Analysis}

Using these current malnutrition rates above, Akinyele, 2005 gave a thought provoking analysis of their implications on survival, education and productivity using the nutrition advocacy tool PROFILES and the result is worrisome. The profile analysis shows that:

- One infant in ten died before the $1^{\text {st }}$ birthday and one child in six died before the age of five.

- $21 \%$ of infant deaths were related to poor breastfeeding practices in Nigeria. If action is not taken to promote and support breastfeeding, 1 million Nigerian infants will die between now and 2015. This represents 275 infant deaths per day for the next 10 years.

- $60 \%$ of child death is related to Protein-Energy Malnutrition (PEM) making it the greatest cause of child mortality. If action is not taken, PEM will be the underlying cause of about 2.5 million child deaths between now and 2015. This is about 700 deaths per day in the next 10 years. This figure outweighs 5 times the estimated number of child deaths attributable to HIV/AIDS over the same period of time.

- If no action is taken to eradicate VAD, about 860,000 Nigerian children will die between now and year 2015.

- Anaemia affects as many as $61 \%$ of women in some regions of Nigeria. If action is not taken, 64,000 Nigerian mothers will die between now and the year 2015, which is about 18 maternal deaths per day everyday for the next 10 years. For the mothers, it will mean killing the hen that lays the golden egg.

- Iron deficiency anaemia also limits children's intellectual development and learning capacity of infants and young children. In Nigeria, $29 \%$ of children under 5 years of age are anaemic and is as high as $50 \%$ in some regions.

- Over $20 \%$ of the total populations suffer goiter, the most severe form of iodine deficiency. If current levels of iodine deficiency remain unchanged, over 9 million children born between 2005 and the year 2015 will suffer from varying degrees of mental impairments because their mothers were deficient in iodine during pregnancy. Endemic iodine deficiency reduces Intelligent Quotient (IQ) by 3.5\% thereby affecting intellectual development permanently.

UNICEF's damage assessment report for Nigeria in 2006 corroborates the above figures as shown below:

\subsection{VITAMIN \& MINERAL (VM) DEFICIENCY: A damage assessment report for Nigeria}

The damage being inflicted by VM deficiency on the people and the nation of Nigeria has been estimated as follows:

- Approximately $40 \%$ to $60 \%$ of the nation's 6 -to- 24 month-old children are at risk of disrupted brain development. Cause: Iron deficiency

- An estimated 350,000 Nigerian babies born each year with intellectual impairment caused by iodine deficiency in pregnancy. In countries where the goiter rate is $10 \%$ or more (Nigeria just under $10 \%$ ), more moderate forms of iodine deficiency are estimated to be so widespread as to lower the average national Intelligent Quotient (IQ) by as much as 10 to 15 percentage points. 
- The deaths of over 80,000 children each year from increased susceptibility to infection. Cause: Vitamin A deficiency

- Approximately $25 \%$ of Nigerian children grow up with lowered immunity, leading to frequent ill health and poor growth. Cause: Vitamin A deficiency.

- An estimated 11,000 deaths among young Nigerian women every year in pregnancy and childbirth. Cause: severe iron deficiency anaemia.

- Approximately 100,000 Nigerian infants a year are at increased risk of death in the period immediately before or after birth. Cause: severe anaemia in mothers.

- Approximately 9,000 severe birth defects annually, including infantile paralysis.

\section{Cause: Folate deficiency}

- $\quad$ Suspected increase in deaths from heart disease and stroke. Cause: Folate deficiency

- Lowered productivity of adult work-force. Loss to Nigeria estimated at $0.7 \%$ of GDP. Cause: iron and iodine deficiency.

- $\quad$ Significant but unmeasured burden on health services, educational systems, and on families caring for children left disabled or mentally impaired.

- These figures in a country with a total population of 140 million are staggering and portend danger and enormous damage. It implies that many children and mothers are living in unhealthy health status. Yet children are the future leaders and hope of a nation. Nigeria indeed has malnutrition crisis and decisive decision must be taken. If it has been neglected in the past, we can no longer afford to ignore it now because the crisis has reached a crescendo level. Effort must be made to meet the Millennium Development Goal of eradicating malnutrition in 2015.

\section{Was nutrition neglected in Nigeria to result in this crisis?}

Developed countries have specific budget for nutrition. For example, in USA $15 \%$ of the Gross National Product (GNP) is on health expenditure. But according to Olanyinka, 2005, unfortunately, government has neglected nutrition and most ministries have no specific budget line item for nutrition which may explain why the rate of malnutrition is high in Nigeria and incidences of diet related diseases are on the increase throughout the population. The micronutrient content of foods is a hidden quality to the uninformed consumer and their deficiencies are referred to as "hidden hunger". Calories can be detected more easily than them since people know when they are hungry and when they are full. There is no natural hunger for vitamin A, iron, iodine, folate, zinc, etc. Signs of their inadequate consumption by a person are subtle and delayed and may not seem severe or diet-related to the individual directly affected. However, by the time they manifest clinically, they would have done much harm that might be difficult to reverse. They could be referred to as "silent killers" or "smooth operators". For example, vitamin A deficiency (VAD). VAD is a hidden hunger because subclinical forms of VAD may not cause any symptoms but the risk of developing respiratory and diarrheal infections is increased, the growth rate is decreased, and the bone development is slowed, and some of the patients may complain of VAD anaemia also called the anaemia of vitamin A (increased fatigue) (Thakore and Gopalswamy, 2006). This is why they are neglected and neglecting them signifies a blink future for children, pregnant and lactating mothers.

Another serious implication of neglecting good nutrition is that nutrient deficiencies coexist in a population. The presence of one triggers off another if prolonged. For example, if prolonged energy deficiency becomes severe, a form of PEM called Marasmus results. When this progresses and inadequate intake of nutrients, including protein, is combined with an already existing disease, a form of malnutrition called kwashiorkor develops. Marasmus and kwashiorkor can exist in the same person. PEM can exacerbate measles and VAD (Wardlaw and Kessel, 2002). Protein deficiency affects carotenoid absorption. It triggers off other secondary infections such as low serum albumin, mineral deficiencies such as iron, zinc and copper (Winkes, 2002; Rahman, 2002). Zinc deficiency interferes with Retinyl binding protein which transports vitamin A. Each of these deficiencies, in turn triggers of vitamin A deficiency. Zinc deficiency and VAD coexist in malnourished children (Rahman, 2002). In zinc deficiency, impaired synthesis of protein occurs with rapid turnover (Thakore and Gopalswamy, 2006). VAD exacerbates measles, diarrhoea, dysentery, zinc deficiency, HIV/AIDS etc. VAD and zinc coexist in malnourished children (Rahman, 2002). It affects the synthesis of zinc dependent binding protein and therefore the absorption and lymphatic transport of zinc. It is a chain reaction. There is a synergy effect. Vitamin A 
deficiency impairs iron utilization (VGI, 1997). A synergistic relationship between vitamin A and iron has been demonstrated (Mwanri et al. 2000).

\section{Scientific evidence for taking decisive action}

Studies have demonstrated that the silent crisis of malnutrition can be eradicated through dietary strategies such as micronutrient supplementation, food fortification, dietary diversification, nutrition education, biofortification etc. Vitamin A and iron are of public health concern during pregnancy in Indonesia. Tanumihardjo (2002) sought to determine the effects of vitamin A and iron supplementation on the vitamin A and iron status of pregnant Indonesian women. They found that their vitamin A and iron status were significantly improved by vitamin A and iron supplementation. In a related study, Tyson et al. (1999), in their study of vitamin A supplementation for extremely-low-birth-weight-infants, reported that intramuscular administration of 5000 i.u. of vitamin A three times per week for four weeks reduced the risk of chronic lung disease in extremely-low-birth weight-infants. Mwanri et al. (2000) investigated the impact of dietary supplements on anaemia and anthropometric indices of anaemic school children in Tanzania. Their conclusion is that vitamin A supplementation may have a useful role in combating the problems of vitamin A deficiency (VAD) and anaemia, as well as improving children's growth in developing countries. Vitamin A deficiency and Zinc often coexist in malnourished children. Zinc deficiency limits the bioavailability of vitamin A. Rahman et al. (2002) conducted a randomized, double-blind, placebo-controlled intervention trial to evaluate whether combining zinc and vitamin A supplementation would improve the biochemical indexes of vitamin A nutriture. They found that combined zinc and vitamin A supplementation improved the vitamin A nutriture in vitamin A-deficient children. Rahmathullah et al. (2003) in their supplemental trials of vitamin A to pregnant mothers and infants to determine the best time to give vitamin A to reduce mortality in the first six months of life found that the more effective strategy is supplementation immediately after birth. This study agrees with the findings of Humphrey et al. (1996). Their study on impact of neonatal vitamin A supplementation on infant morbidity and mortality concluded that the use of vitamin A supplement at birth can help to prevent against infant mortality and illness. Aravind Center for Women, Children and Community Health, Madurai, Tamil Nadu, India in their study of Impact of supplementing newborn infants with vitamin A on early infant mortality in a community based randomized trial in Southern India corroborates the above findings. They also reported that vitamin A supplement in the first days of life can help to reduce the risk of death. Semba et al. (2002) looked at the role of VAD in hyperetinolemia, night blindness and Bitot's spots. A total of 236 young children were given either vitamin A supplement or a placebo. The vitamin A supplements helped to increase the amounts of vitamin A that was absorbed by the children. The supplementation helped to decrease the risk of disease. They concluded that the use of vitamin A supplement can help to avoid deficiency and the resulting illnesses associated with VAD.

Based on the Guatemalan program of vitamin A fortification of sugar, a longitudinal evaluation on serum retinol levels of preschool-aged children was performed. The result indicated the effectiveness of the program in raising serum retinol levels (Arroyave, et al. 1981). This finding agrees with that of Solon et al. (2000). They assessed the efficacy of consumption of a vitamin A-fortified wheat-flour bun (pandesal) on the vitamin A status of school-aged children and found that daily consumption of vitamin A-fortified pandesal significantly improved the vitamin A status of Filipino school-aged children with marginal-to-low initial serum retinol concentrations. In another related study, Cabalda, et al. (2009) also determined the efficacy of pandesal baked from wheat flour with iron, with or without vitamin A (VA), in improving anaemic schoolchildren's iron and anthropometric status. Their study showed that in a non-malaria-endemic area, iron fortification of flour significantly reduced the prevalence of iron deficiency among anaemic school children and double fortification with iron and vitamin A significantly improved Haemoglobin $(\mathrm{Hb})$ status. Also, the effect of vitamin A-fortified coconut cooking oil on the serum retinol concentration of Filipino children 4-7 years old was conducted in a 6-month intervention trial. Intake of vitamin A-fortified coconut cooking oil combined with vitamin A rich foods was found to be necessary to increase serum-retinol concentration. They then recommended a vigorous promotion of the consumption of vitamin A-fortified cooking oil together with other vitamin A rich sources to sustain the prevention and control of vitamin A deficiency (Candelaria et al. 2005).

\section{What must be done?}

A synchronized action rather than a fire brigade approach need to be taken at the National, State, Local Government and household levels to be able to address the basic, underlying and immediate causes of malnutrition in Nigeria. Decisions taken to fight this crisis must be proactive, broad-based and sustainable with a long-term effect. Improving the vitamin A status of children with deficiencies (aged 6-59 months), can reduce rates of death from measles by $50 \%$, rates of death from diarrhoea by $33 \%$, and risk rates from all causes of mortality by $23 \%$ (Thakore and Gopalswamy, 2006). Reducing iron deficiency could lower the worldwide 
maternal death toll by more than a third, while increasing work capacity by up to $40 \%$. Providing sufficient iodine could raise the IQ of the population by 10-15 points. The economic impacts are even more impressive. World Bank economists estimate that micronutrient malnutrition drains as much as $50 \%$ of Gross Domestic Product, while comprehensive solutions could cost less than 0.30\% (Bowley, 1997).

Lessons must be learnt from other countries and transferred. VAD is virtually under control in Nicaragua, Vietnam, Venezuela, Indonesia, Bangladesh and some parts of India (West, 2002; UNICEF, 2004). Preventive, food-based and intervention strategies must be adopted and focused on the poor and on parts of the country with high malnutrition and declining health trends.

\section{Food-based intervention strategies}

1). Re-introduction of agricultural programmes to encourage food production. For example Green Revolution, Operation Feed the Nation, home gardening, animal husbandry, fishing, fishery production, snail farming, etc. These must go with provision of adequate storage facilities and good roads for transportation of farm products from rural to urban areas.

2). Biofortification: Is the breeding of crops that load vitamins and minerals into their seeds and roots. A new approach also supported by the Gates Foundation, World Bank and the European Commission is Harvest Plus, a biofortification program of the consultative Group on International Agricultural Research. Netherland is taking a leading role here. An example is Golden rice, a bioengineered provitamin A enriched rice in India and Philippine. Up to $73 \%$ of energy intake in Asian countries can be from rice. So enrichment of rice with vitamin A has the potential to increase vitamin A intake. It was suggested that vitamin A contribution from golden rice will provide $50 \%$ of the RDA. Biofortification of rice with iron, zinc and lutein are possible.

3). Nutrition Education. Female adult illiteracy is still high and there is a correlation between female education and nutrition knowledge. Female adult literacy in Nigeria is 56\% (Akinyele, 2005). In most cases, the cause of protein deficiency or kwashiorkor is intake of poor quality protein rather than inadequate quantity over a prolonged period of time (Joshi, 2003). Dietary fat is essential for the absorption of vitamin A especially beta-carotene. Vitamin $\mathrm{C}$ enhances iron absorption. Rice is a staple food in Nigeria but lacks quality protein. Consumption of rice together with beans compliments the protein quality of rice. Fruits and vegetables should be eaten together with meals to enhance digestion rather than eating them separately. Consumption of local diets should be encouraged rather than habitual intake of fast foods.

4). Diet diversification: People must eat a wide variety of plant foods to be able to have multiple nutrients in their diet to aid digestion, absorption and utilization e.g. fruits and vegetables. More local plant foods rich in nutrients should be identified and promoted. Orange-fleshed sweet potato has been promoted as a rich source of vitamin A in Uganda, Brazil, and Burkina Faso. Researchers have concluded that adding as little as 100g of orange-fleshed sweet potato to the daily diet could eliminate or significantly reduce vitamin A deficiency in children and their mothers (Kanpinga et al. 2004).

5). Breastfeeding from vitamin A sufficient mothers should be encouraged and monitored in our hospitals to ensure compliance. Breast milk is an excellent source of vitamin A for all infants. If the vitamin A and iodine status of the infant's mother is healthy, breast milk is an adequate sole source of this nutrient for the first 6 months of life (FAO/ILSI, 1997). Colostrum is high in vitamin A. Mothers should be encouraged to initiate breastfeeding earlier and to feed their children colostrum. This strategy has been applied successfully in Bangladesh. In some countries, colostrum is believed to be harmful and so thrown away. Breastfeeding conserves iron stores for nursing mothers after iron secreted in the breast milk is deducted (FAO/ILSI, 1997).

6). Complimentary feeding with high nutrient density should also be encouraged for children between six months to two years.

7). Food supplementation: Use of high-dose vitamin A capsules. This is effective but a short-term strategy, costly and not sustainable. It is more efficient if used in conjunction with other strategies.

8). Food fortification: The addition of nutrients to food in amounts contained or not previously contained to enrich the food. This is a long-term approach, most cost-effective and sustainable. It has been practiced globally and is successful. Sugar, margarine and vegetable oil has been fortified in Nigeria according to label claims. Wheat flour has also been fortified with vitamin A, iron, niacin, thiamin (vitamin B1) and riboflavin (vitamin B2). Salt has been fortified with iodine. In fact about $95 \%$ household eat iodized salt in Nigeria. Fortification of salt with multiple nutrients (vitamin A, iron, and iodine) has been experimented in Nigeria and Kenya. Minimal losses of iodine and iron were found but the vitamin A component fell $40 \%-80 \%$. However, because no special precautions were taken to exclude light, the authors felt that the result could be improved (Diosady, et al. 2004). 
Triple fortification of salt with the above nutrients was successful in Switzerland. Biscuit has been fortified with red palm oil as a source of beta carotene in South Africa and this provides about $30 \%$ of the RDA of preschool children in their school lunch. Our rich red palm oil resources should be exploited. Rice has been fortified with vitamin A in USA (Ultra rice).

9). New foods and food preparations: Has been shown to be acceptable and effective. For example, a bread spread has been made from red palm oil in Burkina Faso and South Africa.

10). Novel foods: In Indonesia, a novel way of increasing the vitamin A content of foods has been found to be very effective. Vitamin A contents of eggs were increased by feeding hens a diet containing Spirulina, a blue green algae that contains a high content of beta-carotene and xanthophylls. The highest level of Spirulina diet $(1.5 \%)$ gave the lowest cholesterol content $(133 \mathrm{mg} / 10 \mathrm{~g}$ fresh egg yolk) and the highest retinol content $(0.266 \mathrm{mg}$ retinol $/ 100 \mathrm{~g}$ egg yolk) while the highest cholesterol content resulted from the control diet $(178 \mathrm{mg} / 10 \mathrm{~g}$ fresh egg yolk). The retinol content resulting from the high-Spirulina diet was 2.4 times that present in commercial chicken eggs: equivalent to $266 \mathrm{RE}$ and contributing $48 \%$ of the infant RDA (Piliang et al, 2004).

11). School feeding programmes. Micronutrient fortified snacks and meals can be used for school meals for children as done in Guatemala and South Africa. The beta-carotene fortified biscuit produced in South Africa provided about $30 \%$ of the RDA of preschool children in their school lunch.

12). Homestead production and improved food processing and storage

\section{References}

Ag Bendech M., Some I. T., Vebamba O., Tarini A., BakerS. K. and Zagre N.M. (2004). Carotenoid content of ten varieties of orange-fleshed sweet potatoes promoted in Burkina Faso. A Report of XX11 International Vitamin A Consultative Group meeting Lima, Peru, 15-17 November 2004. Pp 70.

Akinyele O. (2005). Poverty, malnutrition and the Public Health dilemma of disease. University of Ibadan Post graduate school $25^{\text {th }}$ interdisciplinary Research Discourse 2005. PP 1-45.

Aravind Centre for Women, Children and Community Health, Madurai, Tamil Nadu, India (2003). Impact of Supplementing newborn infants with vitamin A on early infant mortality: Community based randomized trial in Southern India. B. M. J., 327 (7409):254.

Arroyare G., Mejia L. A., and Aguilar J. R. (1981). The effect of vitamin A fortification of sugar on the serum vitamin a levels of preschool Guatemalan children: a longitudinal evaluation. Am. J. Clin. Nutr, Vol. 34, 41-49.

Aworh O.C. (2004). Food Preservation: The art, science and technology. University of Ibadan Postgraduate School, $17^{\text {th }}$ Interdisciplinary Research Discourse 2004.

Begin F. and Greig A. (2002). Food fortification in West Africa. Assessment of Opportunities and strategies. The Micronutrient Initiative, October 2002.

Black M. M. (2003). Micronutrient deficiencies and Cognitive functioning. J. Nutr. 133; 3927S-3931S, November 2003.

Bowley A. (1997). Focus on Food fortification to end micronutrient malnutrition. A special symposium held at the International Congress of Nutrition, Montreal, Canada on Saturday, July 26, 1997.

Braun J. V. (2005). 42 Million Children may be hungry in Africa by 2025. International Food Policy Research Institute Release (Aug. 15, 2005) Report. [Online] Available: http://news.mongabay.com/2005/0815-ifpri.html. (6/5/2010).

Cabalda A. B., RND, Tengco L. W., RND, MSc, Solon J. A., MD, MSc, DTM \& H, Sarol J. N., PhD, Rayco-Salon P., MD, MSc, DTM \& H and Solon F. S., MD, MPH. (2009). Efficacy of Pandesal Baked from Wheat flour fortified with Iron and Vitamin A in Imporoving the Iron and Anthropometric Status of Anaemic School children in the Philippines. Am. J. Nutr., Vol. 28, No. 5, $591-600$.

Candelaria L. V., Magsadia C. R., Velasco R. E., Pedro R. A., Corazon V. B., and Tanchoco C. C. (2005). The effect of vitamin A-fortified coconut cooking oil on the serum retinol concentration of Filipino children 4-7 years old. Report of XX11 International Vitamin A Consultative Group meeting Lima, Peru, 15-17 November 2004. Pp 74.

Castejon H.V., Ortega P., Amaya D., Leal J. and Gomez G. (2004). Co-existence of micro and macronutrient deficiencies among children 24-84 months old in Maracaiho, Venezuela. Report of XX11 International Vitamin A Consultative Group meeting Lima, Peru, 15-17 November 2004. Pp 84. 
Datta K., Parkhi V., Rai M., Baisakh N., Torrizo L., Abrigo E., Oliva N., Khalekuzz-aman M. D., Rehana S., and Datta S. K. (2004). Bioengineered provitamin A enriched Tropical Rice. Report of XX11 International Vitamin A Consultative Group meeting Lima, Peru, 15-17 November 2004. Pp 74.

Diosady L.L., Oshinowo T., and Rutkowski K. (2004). Stability of salt triple fortified with iodine, iron and vitamin A. Report of XX11 International Vitamin A Consultative Group meeting Lima, Peru, 15-17 November 2004. Pp 72.

E-Siong T. (1995). The Medical importance of vitamin A and carotenoids (with particular reference to developing countries) and their determination. Mal. J. Nutr. 1:179-230, 1995.

Falase, A.O. (2005). Opening Address at University of Ibadan Post - graduate school $25^{\text {th }}$ Interdisciplinary Research Discourse held on Tuesday, $1^{\text {st }}$ March, 2005 PP. iv-vi.

FAO/ILSI. (1997). Preventing Micronutrient Malnutrition: A guide to food-based Approaches. A manual for policy-makers and programme planners.

Flour Fortification Initiative (FFI). (2008). Summary Report. Second Technical Workshop on Wheat Flour Fortification Practical Recommendations for National application. March 30 to April3, 2008. Stone Mountain, Georgia, USA. Pp 1-8.

Humphrey J. H., Agoestina t., Wu L., nurachim M., Subardja D., Hidayat S., Tielsch J., West K. P. Jr. and Sommer A. (1996). Impact of neonatal vitamin A supplementation on infant morbidity and mortality. J. Ped., 128 (4): 489-96.

InterAcademy Council. (2004). 42 Million Children may be hungry in Africa by 2025. International Food Policy Research Institute Release Report. [Online] Available: http://news.mongabay.com/2005/0815-ifpri.html. $(5 / 5 / 2010)$.

IVACG. (2004).Vitamin A and the common Agenda for micronutrients. Report of the XXII International Vitamin A Consultative Group meeting, Lima, Peru, 15-17 November 2004. Pp 27-100.

Joshi S.A. (2003). Vitamins. In: Nutrition and Dietetics. $2^{\text {nd }}$ edition. Tuta McGraw - Hill Publishing Company Limited, New Delhi. PP. 9-11.

Kapinga R., Anderson P., Zhang D., Herman M., and Oplo F. (2004). Vitamin A deficiency through increased utilization of orange-fleshed sweet potato. A Report of the XXII International Vitamin A Consultative Group meeting Lima, Peru, 15-17 November 2004. Pp 70.

Keusch. (2004). Report of the XXII International VA Consultative Group meeting, Lima, Peru, 15-17 November 2004. P 27-100.

Miller M., Humphrey J., Johnson E., Marinda E., Brookmeyer R. and Katz J. (2002). Why do children vitamin A deficient? Proceedings of the XX int'l Vit. A consultative group meeting. J. Nutr, 132:28675-28805.

Mwanri L., Worsley A., Ryan P., and Masika J. (2000). Supplemental Vitamin A Improves Anaemia and Growth in Anaemic school children in Tanzania. J. Nutr. 130:2691-2696.

Naidoo J. (2006). Africa Fighting Back Against "Hidden Hunger in children". [Online] Available: http://www.micronutrient.org/VMD/country files/NigeriaNSP.html (June 29 2006). Pp. 1-3. (7/5/2010).

Nestel P., Bouis H.E., Meenakshi J.V. \& Pfeiffer W. (2006). Bio-fortification of staple food crops. J. Nutr., 136: 1064-1067.

NIH. (2007). Dietary Supplement Fact Sheet: Vitamin A and Carotenoids. [Online] Available: http://ods.od.nih.gov/factsheets/vitamins.asp P.1-11 (6/5/2010).

Nilson A. and Piza J. (1998). Food fortification: A tool for fighting hidden huger. Fd. And Nutr. Bull, vol.19, no.1. Pp. 49-59.

Nnam N. M. (2004). Effects of Baobab leaf (Adansonia Digitata L.) diet on Vitamin A and Iron status of Nigerian children. Report of the XXII International Vitamin A Consultative Group meeting Lima, Peru, 15-17 November 2004. Pp 66.

Nnam N.M and Onyeke N. G. (2004). Sorrel Calyx (Hibiscus sabdariffa) as a promising source of beta-carotene to control Vitamin A deficiency. A Report of the XXII International Vitamin A Consultative Group meeting Lima, Peru, 15-17 November 2004. Pp 66. 
Piliang W. G., Shatiti W., Panji T., and Pambudi W. (2004). Increasing the vitamin A by consuming chicken egg produced from hens fed Spirulina. Report of XX11 International Vitamin A Consultative Group meeting Lima, Peru, 15-17 November 2004. Pp 74.

Rahman M. M., Wahed M. A., Funchs G. J., Baqui A. H., and Alvarez J. O. (2002). Synergistic effect of zinc and vitamin $\mathrm{A}$ on the biochemical indexes of vitamin A nutrition in children. Am. J. Clin. Nutr., 75:92-8.

Rahman M., Wahed M., Fuchs G., Basque A., and Alvarez J. (2002). Synergistic effect of Zinc \& Vitamin A on the bio-chemical indexes of Vitamin A nutrition in children. J. Clin. Nutr., 75:92-8.

Rahmathullah L., Tielsch J. M., and Thulasiraj R. D. (2003). Impact of supplementing new-born infants with vitamin a on early infant mortality: Community based randomized trial in southern India. Brit. Med. J., 327:254-257.

Ramakrishnan U. and Darn-Hill I. (2002). Assessment and control of vitamin A deficiency disorders. Proceedings of the XX International Vitamin A Consultative Group Meeting. J. Nutr., 132: 2947S - 2953S.

Sanusi R.A., Badejo C.A. and Yusuf B.O. (2006). Measuring Household food Insecurity in selected Local Government Areas of Lagos \& Ibadan, Nigeria. Pakistan J. of Nutri, 5(1): 62-67 PP. 62-67.

Semba R. D., West K. P.Jr., Natadisastra G., Eisinger W., Lan Y. and Sommer A. (2000). Vitamin A deficiency in hyperetinolemia. Am. J. of Clin. Nutr. 72 (1):146-53.

Solon F. S., Klemm R. D. W., Sanchez L., Darnton-Hill I., Craft N. E., Christian P., and West K. P.Jr. (2000). Efficacy of a vitamin A-fortified wheat-flour bun on the vitamin A status of Filipino school children. Am. J. Clin. Nutr. Vol. 72, no. 3, 738-744.

Tang. (2006). Diet, Physical activity or environmental change: What are the key factors underlying the emerging child obesity epidemic in Ho Chi Minh City, Vietnam? Nestle Report, 2006. p. 21.

Tanumihardjo S. A. (2002). Vitamin A and iron status are improved vitamin a and iron supplementation in pregnant Indonesian women. J. Nutr. 132:1909-1912.

The Philippine Food Fortification programme. [Online] Available: http://www.doh.gov.ph/food fortification/downloads/history.pdf. (January 9, 2007).

Tyson J. E., Wright L.L., Oh W., Kennedy K. A., Mele L., Ehrenkranz R. A., Stoll B. J., Lemons J. A., Stevenson D. K., Bauer C. R., Korones S. B., and Fanaroff A. A. (1999). Vitamin A Supplementation for extremely-low-Birth-Weight Infants. N. Engl. J. Med. 340 no. 25:1962 - 8 .

UNICEF. (1998). Full Report of the meeting of the Working Group on Vitamin A deficiency. Sunday 29 March 1998, Oslo, Norway. Pp 1-6.

UNICEF. (1998). Report of Informal Technical Consultation on Vitamin A, December 1997, New York, Pp 6.

United Nations Children's Fund (UNICEF). (1996). Current events and recent data. Fortification update, no. 1(1995). Retrieved from http://www.unicef.org.htm/. (29/6/2006)

van Jaarsveld P. J., Faber M., Tanumhardjo, Nestle P., Lombard C. J., and Benade A. J. S. (2004). Beta-carotene -Rich-Orange fleshed sweet potato improves vitamin A status of primary school children in South Africa. Report of XX11 International Vitamin A Consultative Group meeting Lima, Peru, 15-17 November 2004. Pp 74.

van Jaarsveld P. J., Marais D. W., Harmse E., Laurie S. M., Nestle P. and Rodriguez-Amaya. (2004). Beta-carotene content of sun-dried and oven-dried chips of orange-fleshed sweet potato. Report of XX11 International Vitamin A Consultative Group meeting Lima, Peru, 15-17 November 2004. Pp 70.

van Stuijvenberg M. E., Marais D., Wolmaraus P., Schoeman S. and Benade A. J. S. (2004). A red-palm oil-based bread spread to alleviate vitamin A deficiency in secondary school children. A Report of the XXII International Vitamin A Consultative Group meeting Lima, Peru, 15-17 November 2004. Pp 68.

Vitamin Global Initiative (VGI). (1997). A Strategy for Acceleration of Progress in Combating Vitamin A Deficiency. Consensus of an Informal Technical Consultation convened by UNICEF/MI/WHO/CIDA/USAID. New York, 18-19 December, 1997. Pp 19-70.

Wardlaw G.M and Kessel M. (2002). Vitamin A. In: Perspectives in nutrition, $5^{\text {th }}$ edition. McGraw Hill, Boston, Toronto. Pp 792-818.

West K. P., Jr., Klemm R., Dary O., Johnson Q., Randal P., and Northrop-Clewes C. (2008). Background document prepared for the Second Technical Workshop on Wheat Flour Fortification Atlanta, GA. 31 March-3 April 2008. Vitamin A Fortification Working Group. Draft. $31^{\text {st }}$ March, 2008. 
West K.P., Jr., Klemm R., Dary O., Johnson Q., Randal P., and Northrop-Clewes C. (2008). Background document prepared for the second Technical workshop on wheat flour fortification Atlanta, GA. 31 March-3 April 2008. Vitamin A Fotrification Working Group Draft. 31 ${ }^{\text {st }}$ March 2008.

WHO. (2008). Micronutrient deficiencies: Vitamin A deficiency. Retrieved from http://www.who.int/nutrition/topics/vad/en/. (January 8, 2010).

Winkes A. (2002). Malnutrition \& Vitamin deficiencies. Case-based Pediatrics for Medical students and Residents. Department of Pediatrics, University of Hawaii John A. Burns School of Medicine.

Zagre N. M., Delishe H., Delpeuch F. and Traissac P. (2004). Moving with Red palm oil towards dietary diversification strategy for controlling vitamin A deficiency in Burkina Faso. A Report of XX11 International Vitamin A Consultative Group meeting Lima, Peru, 15-17 November 2004. Pp 68.

Zimmermann M., Wegmuller R., Zeder C., Chaouki N., Rohner F., Torresani T., and Hurrell R. (2004). Report of XX11 International Vitamin A Consultative Group meeting Lima, Peru, 15-17 November 2004. Pp 75.

Table 1. Malnutrition Status in Nigeria.

\begin{tabular}{|c|c|c|}
\hline PEM Indicators: U5MR & Children & Mothers \\
\hline Stunted & $42 \%$ & - \\
\hline Wasted & $9 \%$ & - \\
\hline Underweight & $25 \%$ & $13 \%$ \\
\hline Micronutrient deficiency Indicators & & $24.3 \%$ \\
\hline Vitamin A deficient & $25 \%$ & $35.3 \%$ (Pregnant mothers) \\
\hline Iron deficiency & $27.5 \%$ & $30.7 \%$ \\
\hline Iodine deficiency & $27.5 \%$ & $28.1 \%$ \\
\hline Zinc deficiency & $20 \%$ & $43.8 \%$ (Pregnant mothers) \\
\hline
\end{tabular}

Source: Micronutrient Initiative, 2004; Akinyele, 2005.

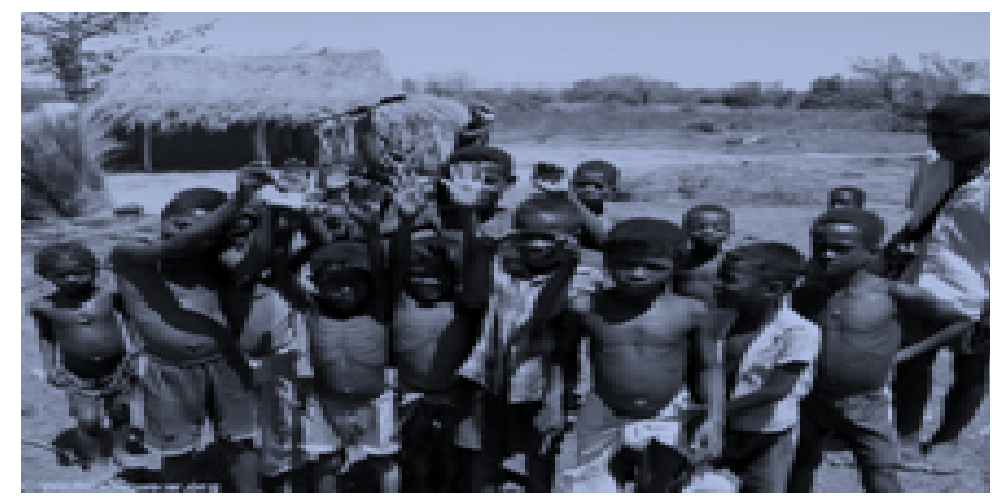

Figure 1. Malnourished children 